\title{
Normative Data of Cepstral and Spectral Measures in Korean Adults Using Vowel Phonation and Passage Reading Tasks
}

\author{
Seung Jin Lee ${ }^{\mathrm{a}}$, Hwa Young Pyo ${ }^{\mathrm{b}}$, Hong-Shik Choi ${ }^{\mathrm{a}}$ \\ ${ }^{a}$ Department of Otorhinolaryngology and the Institute of Logopedics and Phoniatrics, Yonsei University College of Medicine, Seoul, Korea \\ ${ }^{b}$ Department of Speech-Language Pathology, College of Health Science, Chosun University, Gwangju, Korea
}

Correspondence: Hong-Shik Choi, MD, PhD Department of Otorhinolaryngology and the Institute of Logopedics and Phoniatrics, Yonsei University College of Medicine, 211 Eonju-ro, Gangnam-gu, Seoul 06273, Korea

Tel: +82-2-2019-3461

Fax: $+82-2-3463-4750$

E-mail: hschoi@yuhs.ac

Received: January 20, 2018

Revised: March 1, 2018

Accepted: March 5, 2018
Objectives: The purpose of the present study was to construct local normative data for cepstral and spectral measures in Korean adults without voice impairments by using vowel phonation and passage reading tasks, and to investigate whether those measures differ according to gender and the measurement positions in a passage. Furthermore, the correlation of the measures derived by different tasks was also explored. Methods: One hundred and forty-four community-dwelling adults (age-matched 72 males and 72 females) without speech or language disorders participated in the study. Participants were asked to produce the Korean vowel /a/ and to read the Korean standard passage 'Ga-eul.' Cepstral and spectral measures were obtained for each vowel and sentence sample in front and rear positions of the passage using the Analysis of Dysphonia in Speech and Voice program. For sentence samples, cepstral measures were compared according to gender and position. Results: Males showed significantly higher CPP, CPP $\max _{2}, \mathrm{CPP}_{\min }$, and $\sigma \mathrm{CPP}$ in vowel production tasks, while females showed higher CPP F0 and CPP/Avg. In the passage reading task, a significant interaction effect between gender and position was shown for CPP, $\sigma C P P$, maximum $\mathrm{L} / \mathrm{H}$ ratio, CPP F0, and $\sigma \mathrm{CPP}$ F0. Males showed higher $\mathrm{CPP}_{\max }$ and $\mathrm{L} / \mathrm{H}$ ratio, while females showed higher $\mathrm{CPP}_{\min }$ and $\mathrm{CPP} / \mathrm{Avg}$. The minimum $\mathrm{L} / \mathrm{H}$ ratio was higher for the front position, while the $\sigma \mathrm{L} / \mathrm{H}$ ratio and regression slope were higher for the rear position. Conclusion: The current data could contribute to the diagnosis of voice problems in the Korean population through clinical practice and research, although the differences between tasks should be taken into consideration.

Keywords: Cepstral analysis, Cepstral peak prominence (CPP), L/H ratio, Normative data, Vowel phonation, Passage reading '켑스트럼(cepstrum)'은 음성 신호의 파형을 푸리에 변환한 스펙 트럼 측정치를 로그 변환한 후, 이를 다시 푸리에 역변환한 것이다 (Oppenheim \& Schafer, 2004). 음성 신호에 대한 켑스트럼 분석을 통해 얻어지는 대표적인 측정치로 '켑스트럼 피크 현저성(cepstral peak prominence, $\mathrm{CPP}$ )'이 있는데, 이는 켑스트럼 강도(lampitude) 의 최대값과, 분석 대상이 된 큐프렌시(quefrency) 범위의 켑스트럼 강도에 대한 1 차 함수 형태의 회귀선 간의 거리를 일컫는다(HemanAckah, Michael, \& Goding, 2002; Hillenbrand, Cleveland, \& Erickson, 1994). CPP는 음성장애 중증도에 대한 숙련된 전문가의 청
지각적 평정치와의 높은 상관관계가 보고되면서 주목받고 있다 (Awan, Roy, Zhang, \& Cohen, 2016; Brinca, Batista, Tavares, Gonçalves, \& Moreno, 2014; Fraile \& Godino-Llorente, 2014).

현재 켑스트럼 분석을 수행할 수 있는 다양한 음향학적 분석 프 로그램이 존재하는데, 가장 대표적인 프로그램 중의 하나인 'Analysis of Dysphonia in Speech and Voice (ADSV)' 프로그램(Model 5109, PENTAX Medical)이 최근 연구에 활발하게 이용되어 왔다. $\mathrm{ADSV}$ 는 음성신호의 시간 흐름에 따른 파형(waveform), 스펙트로 그램(spectrogram), 그에 따른 켑스트럼 및 스펙트럼 측정치의 변 
화 추이뿐만 아니라, 특정 시점에서의 측정치 또한 알아보기 쉽게 시각화해주는 장점이 있다(Sauder, Bretl, \& Eadie, 2017). 또한 기본 적으로 여타 신뢰성이 검증된 켑스트럼 분석 프로그램과 마찬가지 로 평활화(smoothing)된 CPP 수치를 제공하며, 켑스트럼 및 스펙 트럼 측정 변수가 전체 샘플에서 갖는 평균치, 표준편차, 최대값, 최 소값 등 다양한 수치를 제공함으로써 해당 음성샘플에 대한 켑스 트럼 분석 측정값의 다양한 측면을 조망할 수 있도록 해준다(KayPentax, 2011). 이와 더불어 이러한 분석에 활용 가능한 여러 단축 키가 프로그램 내에 존재하는 점 또한 임상적인 관점에서 활용을 용이하게 해줄 수 있는 장점의 하나로 여겨진다.

앞서 설명한 $\mathrm{CPP}$ (단위 $\mathrm{dB}$ ) 외에 $\mathrm{ADSV}$ 를 통해 측정할 수 있는 대표적인 변수로는 $\mathrm{CPP}$ 의 표준편차 $(\sigma \mathrm{CPP})$, 최댓값 $\left(\mathrm{CPP}_{\max }\right)$ 및 최 솟값 $\left(\mathrm{CPP}_{\min }\right)$ 뿐만 아니라 $\mathrm{L} / \mathrm{H}$ 비율(low-to-high spectral ratio, $\mathrm{SR}$; 단위 $\mathrm{dB})$ 과 그 표준편차 $(\sigma \mathrm{SR})$, 최댓값 $\left(\mathrm{SR}_{\max }\right)$ 및 최솟값 $\left(\mathrm{SR}_{\min }\right)$ 이 있으며, 그 외에도 평균 $\mathrm{CPP} F(\mathrm{CPP} F$, 단위 $\mathrm{Hz})$, 평균 $\mathrm{CPP}$ (CPP/Avg, 단위 $\mathrm{dB})$, 회귀선 기울기(Slope), 켑스트럼 강도(cepstral intensity, $\mathrm{CI}$; 단위 dB)와 각 변수의 표준편차 $(\sigma \mathrm{CPP} \mathrm{F0,} \sigma \mathrm{CPP} / \mathrm{Avg}$, бSlope, $\sigma \mathrm{CI}$ ) 등도 측정할 수 있다(KayPentax, 2011).

이 측정치들에 대해 간단히 설명하자면 다음과 같다. SR은 선택 된 유성(voiced) 구간 프레임의 $4,000 \mathrm{~Hz}$ 이상 주파수대 에너지에 대한 $4,000 \mathrm{~Hz}$ 이하 주파수대 신호 에너지의 평균 비율이다. CPP $\mathrm{F} 0$ 는 $60-300 \mathrm{~Hz}$ 범위에 해당하는 켑스트럼 피크의 평균 주파수이 며, $\mathrm{CPP} / \mathrm{Avg}$ 는 $60-300 \mathrm{~Hz}$ 범위의 켑스트럼 피크값과 평균 켑스트 럼값 간의 차이이다. Slope은 평활화된 회귀선 기울기 값의 평균값 이며, $\mathrm{CI}$ 는 각각의 선택된 유성 프레임에 대한 켑스트럼 강도 값들 이 포함된 배열(array)의 평균이다. 이 가운데 특히 SR은 음성장애 환자의 음성샘플에서 정상에 비해 낮은 수치를 보이는 경향을 보이 고, $\mathrm{CPP}$ 에 비해 그 신뢰도는 다소 낮으나 여러 연구에서 보조적으 로 이용된다(Lowell, Colton, Kelley, \& Mizia, 2013). 평균 CPP F0 는 켑스트럼 측정치를 기반으로 대상자의 $\mathrm{F} 0$ 를 추정하여 나타낸 것으로, 다른 시간기반 분석방법을 통해 측정한 기본주파수와 대 조 및 확인을 하는 데 주로 사용되었다(Shim et al., 2016). 그 외의 변수들에 대해서는 아직 그 임상적 의의에 대한 연구나 그에 앞서 서 정상 음성의 규준치에 관한 연구도 부족하며, 공식 매뉴얼에도 정상치가 제시되어 있지 않은 실정이다.

켑스트럼 분석은 기식성 음성을 비롯한 장애 음성에 대한 음향학 적 평가에 있어 그 유용성이 다양한 방식으로 검증되어 왔다(Moers et al., 2012). 그럼에도 불구하고, 정상 음성에서 심도의 장애 음 성에 이르기까지 다양한 음성신호에 대한 켑스트럼 분석의 토대가 될 수 있는 정상 측정치에 대한 연구는 아직 부족하며, 국내의 경우
더욱 그러하다(Lee, Lim, \& Choi, 2017a). 많은 국내외의 연구들에 서 장애군을 주요 연구대상으로 하여 특정 중재의 전후 결과를 비 교하여 제시하거나(Kang \& Koo, 2015; Kim, Choi, Lee, \& Jin, 2015; Kim et al., 2016; Seo et al., 2016; Yu, Choi, Choi, \& Lee, 2017), 환자 군의 자료에 대한 적은 수의 정상 대조군 자료를 제한적으로 표집 하였다(Lowell et al., 2013; Park, Mun, Lee, \& Jin, 2013; Shim et al., 2016; Watts \& Awan, 2011). 다만 정상 성인 51명을 대상으로 한 최 근의 한 선행연구(Choi \& Choi, 2016)는 남성 대상자와 저모음에서 $\mathrm{CPP}$ 가 더 높았고, 남성에서 SR의 표준편차가 더욱 컸음을 보고하 였다. 그러나 이 연구의 경우 표본 수가 비교적 제한되어 있으며, 무 엇보다도 표준문단 전체를 분석의 대상으로 삼았다는 한계점이 있 었다. 왜냐하면 선행연구들에서 대부분 문장 수준의 말 자료를 분 석하고 있으므로 이 데이터와의 직접 비교와 해석이 비교적 어렵 고, 문단 내 위치에 따른 차이가 희석될 가능성을 배제할 수 없기 때문이다. 다소 생소한 분석 프로그램과 측정치들에 익숙해져야 하는 부담과 더불어, 정상 측정치의 이러한 부재는 켑스트럼 분석 이 임상 현장에서 아직 널리 이용되지 못하게끔 하는 장벽의 하나 로 작동하는 것으로 여겨진다. 정상 성인 60명을 대상으로 한 다른 국외의 선행연구(Garrett, 2013)에서도 비교적 다양한 모음과 말 자 료를 이용하여 CPP F0를 포함한 정상 측정치를 제시하였으나, 대 상자 수가 비교적 적고, 모든 ADSV 변수에 대해 자료를 제시하지 는 못하였다.

이러한 음향학적 측정치의 정상 규준 자료를 구축하는 데 있어 가장 중요한 고려 요인 중 하나로 성별이 있다. 음성클리닉에서 전 통적으로 사용되어 오던 음향학적 측정치 중 가장 대표적이라고 할 수 있는 '주파수변동률(jitter percent, Jitt), '진폭변동률(shimmer percent, Shim)', 또는 '소음 대 배음비(noise-to-harmonic ratio, NHR)'의 정상 측정치에 대한 국내 선행연구들에서도 성별 차 가 보고되어 왔다(Kim, 2009; Pyo et al., 2002). 따라서, ADSV 측정 치 중 하나인 평균 $\mathrm{CPP} \mathrm{F}$ 가 성별 간 차이를 보일 것이 예상된다는 점을 차치하고라도, 성별에 따른 별도의 규준 자료를 구축하여야 할 필요성이 있으나, 국내 선행연구들에서는 이러한 성별 차이에 대한 고려가 부족한 실정이다(Choi \& Choi, 2016).

성별 차이와 더불어 고려해야 할 요인으로서 최근 한 선행연구에 서는 문단 내 측정 위치에 따른 켑스트럼 및 스펙트럼 측정치의 차 이가 보고되었다(Lee et al., 2017a). 즉 한 표준문단 내의 서로 다른 위치에서 유사한 음소 구성을 가진 문장들을 골라 전반적 중증도 에 대한 청지각적 평정치를 통제한 상태에서 켑스트럼 및 스펙트럼 측정치를 비교한 결과, 뒤쪽의 문장에서 $\mathrm{CPP}$ 측정치가 더 낮고 SR 의 표준편차가 더욱 컸다. 이는 음성 피로(vocal fatigue)의 영향일 
것이라고 추측되었는데, 이러한 결과를 감안한다면 정상 규준 자 료를 구축함에 있어서도 문단 내 위치에 따른 이러한 차이의 가능 성을 염두에 두고 각각의 규준 데이터를 구축하여야 한다. 왜냐하 면, 위치에 따른 차이가 음성장애 유무에 무관하게 나타났고, 이는 표준문단 수준의 글을 읽을 때 정상 대상자 또한 다소 간의 음성 피로를 보여 이것이 규준치에 반영될 가능성이 있기 때문이다.

따라서 본 연구에서는 한국 정상 성인의 모음/ㄱ/ 샘플과 표준문 단 읽기의 연결발화 샘플에서 ADSV를 통해 측정한 켑스트럼 및 스펙트럼 측정치의 성별에 따른 정상 규준 자료를 구축하고자 하 였다. 또한 문단 내 측정위치 및 성별에 따른 측정치를 비교하여 차 이가 있는지 알아보고자 하였다. 마지막으로, 상이한 두 과제를 이 용하여 측정한 주요 측정치들 간에 상관관계가 있는지의 여부를 확인하고자 하였다.

\section{연구방법}

\section{연구대상}

먼저 G*Power (Faul, Erdfelder, Buchner, \& Lang, 2009)를 사용 하여 두 성별 집단과 문단 내 두 위치를 독립변수로, 16 개의 켑스트 럼 및 스펙트럼 측정치를 종속변수로 한 이원 다변량분석(two-way MANOVA)을 위한 최소의 표본 수를 산정한 결과, 142 명이었다 (effect size $f^{2}=.14$, power $=.95$ ). 이에, 본 연구의 대상자는 서울 지 역에 거주하고 있는 정상 음성을 지닌 한국어 모국어 화자 남녀 각 72 명씩, 총 144 명으로 하였다(Table 1). 성별 집단 간 연령 차는 3 세 이내로 일치하도록 하였으며, 연령에 있어서 집단 간 유의한 차이가 없었다 $(t=.308, p=.758)$.

연구대상에서 제외한 기준은 환자의 사례력에 대한 면담을 시행 하여 연구참여일 기준 3 개월 이내에 상기도 감염(upper respiratory infection) 증상 혹은 음성 질환을 주 호소로 이비인후과를 방문한 기왕력이 있거나, 과거 혹은 현재 흡연력이 확인된 자(Choi \& Choi, 2016)는 제외하였다. 이는 혹시라도 있을 수 있는 잠복기의 음성장 애를 배제하기 위한 조치였다. 또한 검사 과정에서 시력 문제나 읽 기 문제가 보고되거나 관찰되는 경우도 제외하였다. 마지막으로 대

Table 1. Demographic data of the participants

\begin{tabular}{lcc}
\hline & Male (N=72) & Female ( $=72)$ \\
\hline Age (yr) & $28.57 \pm 7.88(19-49)$ & $28.17 \pm 7.80(19-49)$ \\
K-VAPP $_{\text {TL }}$ & $2.58 \pm 2.36$ & $3.54 \pm 3.73$ \\
\hline
\end{tabular}

Values are presented as mean $\pm S D$ and range (min-max).

$\mathrm{K}_{\mathrm{VAPP}} \mathrm{\pi L}=$ total score of the Korean version of the Voice Activity and Participation Profile (maximum $=280$, cut-off score $=14.5$ ).
학병원 이비인후과의 음성클리닉에서 4 년의 음성 평가 및 치료, 연 구경력을 지닌 1 인의 1 급 언어재활사(제 1 저자, 언어병리학박사)가 모음 및 연결발화에 대한 녹음 시 GRBAS (Hirano, 1981) 척도를 이용한 청지각적 평정을 시행하고, 대상자 본인이 음성 활동 및 참 여 프로파일-한국판(Korean version of the Voice Activity and Participation Profile, K-VAPP) 설문지를 작성하도록 하였다. 이를 토 대로 임상가(GRBAS 척도의 G 척도상 0 이 아닌 자) 혹은 대상자 (K-VAPP 총점의 절단점인 14.5점 기준)에 의하여 유의한 수준의 주관적인 음성장애가 인지된 경우 또한 연구대상에서 제외하였다 (Lee et al., 2016).

\section{녹음 환경}

음성 녹음의 환경은 음성 자료의 녹음 세팅에 관한 미국의 국립 음성말센터(The National Center for Voice and Speech)의 기술 보 고서를 참고하여 적정 수준의 필수적인 구성요소를 모두 갖추도록 구성하였다. 먼저 모든 녹음은 조용한 방에서 이루어졌으며, 소음 측정기(Voltcraft Datalogger 322; Conrad Electronic, Hirschau, Germany)를 이용하여 $50 \mathrm{~dB}$ 이내로 환경 소음을 통제하였다. 컴 퓨터로는 팬 소음이 발생하지 않는 팬리스 태블릿 PC (Microsoft Surface Pro 4, Core m3 model), USB 연결이 가능한 오디오 인터페 이스(UR-22; Steinberg Media Technologies GmbH, Hamburg, Germany), 충분한 수준의 증폭 및 음성신호 왜곡 방지를 위한 프 리 앰프(Tube Ultragain MIC200; Behringer GmbH, Kirchardt, Germany), 단일 지향성 다이나믹 마이크(SM48; SHURE, Niles, IL, USA)와 음성 신호의 편집이 용이한 상용 녹음 소프트웨어(Sony Sound Forge Pro 11.0)를 이용하였다(표본추출률 $44,100 \mathrm{~Hz}, 16$ bit 양자화). 마이크는 T자형 스탠드를 이용하여 안정적으로 거치 하였으며, 마이크의 끝부분이 대상자 입술과 정면 직선거리를 10 $\mathrm{cm}$ 가 되도록 유지하였다.

\section{녹음 및 분석}

각 대상자로 하여금 모음//를 편안한 음도와 크기로 가급적 일 정하게 5 초 이상 발성하도록 하였으며, 표준문단인 '가을' 문단(Kim, 2012)을 1회 읽도록 하여 녹음하였다. 이때 평상시 대화를 하듯 자 연스러운 음도 및 크기로 읽도록 지시하였다(Lee, Lim, \& Choi, 2017b). 녹음이 종료된 후에는 wav 확장자 파일로 저장한 후 제1저 자가 트리밍하였다. 모음샘플(144개)은 사운드 포지 프로그램에서 파형을 관찰하며 가능한 한 안정된 구간을 찾아, 지정구간 트리밍 기능을 활용하여 정확하게 4.000 초 길이로 트리밍하여 별도의 파 일로 저장하였다. 반면, 문장샘플은 $\mathrm{ADSV}$ 를 이용하여 문단의 앞 
문장('무엇보다도 산에 오를 땐 더욱 더 그 빼어난 아름다움이 느껴 진다', 26음절)과 뒷문장('독서는 우리에게 마음을 살찌우고 아름 답게 하는 힘을 주기 때문이다', 28 음절) 두 위치의 문장을 트리밍 하여 별도 파일(위치별 144 개, 총 288개)로 저장하였다. 이 두 문장 을 선정한 것은 음절수, 장애음 포함 비율, 다양한 음소구성 측면에 서 비교적 유사하면서도 뒷문장의 $\mathrm{CPP}$ 와 $\mathrm{SR}$ 관련 측정치가 앞부 분 혹은 중간부분과 유의한 차이를 보였다는 선행연구를 참고한 것이다(Lee et al., 2017a).

각 모음샘플에 대해서는 19 개, 문장샘플에 대해서는 16 개의 변 수를 측정하였다. 먼저 모음 및 문장샘플 모두 공통적으로 $\mathrm{ADSV}$ 를 이용하여 $\mathrm{CPP}$ 와 $\mathrm{SR}$ 의 평균, 표준편차 $(\sigma)$, 최대값, 최소값을 측 정하였고, 평균 CPP F0, CPP/Avg, 회귀선 기울기, 켑스트럼 강도의 평균과 표준편차를 측정하였다. 한편 모음샘플에 대해서는 음성의 질과 관련이 있는 것으로 알려진 주기성에 기반을 둔 전통적인 음 향학적 측정 변수 3개(Jitt, Shim, NHR)를 Multi-Dimensional Voice Program (MDVP, CSL model 5105; PENTAX Medical)을 이용하 여 추가적으로 측정하였다.

\section{신뢰도 및 통계분석}

모음 및 문장샘플의 트리밍에 따른 음향학적 측정치의 신뢰도를 확인하기 위하여, 전체 대상자의 $10 \%$ 에 해당하는 15 명의 대상자를 무작위로 선정하여 전술한 모음 및 문장샘플 트리밍 및 분석 절차 를 제 1 저자와 제 2 저자(언어치료학과 교수, 음성장애 임상 및 연구 경력 20년)가 1 회 반복 시행하였다. 측정한 수치에 대하여 신뢰도를 측정하기 위해 각 평가자 간에는 이원혼합모형(two-way mixed model)을, 평가자 내에는 일원변량모형(one-way random model) 을 활용하여 각 변수별로 단일 측도(single measures)의 급내상관 계수(intraclass correlation coefficient, ICC)를 산정하였다. 그 결 과 평가자 간 신뢰도( $\mathrm{CPP}_{\max }$.958- $\sigma \mathrm{CPP}$.998)와 평가자 내 신뢰도 $\left(\mathrm{CPP}_{\max }\right.$.938- $\sigma \mathrm{CPP}$.998)가 모두.9 이상으로 매우 높은수준이었다.

모음 샘플에서 성별 간 켑스트럼 및 스펙트럼 측정치와 전통적 측정치의 차이가 있는지 알아보기 위하여 독립표본 $t$-검정을 시행 하였다. 또한 성별 집단(남성, 여성)과 문단 내 위치(앞, 뒤)에 따라 켑스트럼 및 스펙트럼 측정치의 차이가 있는지 알아보기 위하여 이원 다변량 분석(two-way multivariate analysis of variance, MANOVA)을 수행하였다. 마지막으로 각 과제에 의해 측정된 대표적 인 켑스트럼 및 스펙트럼 측정치 간의 상관관계를 살펴보기 위해, 모음 연장 과제와 문단 내 두 위치에서 측정한 $\mathrm{CPP}, \mathrm{SR}$, 그리고 모 음 연장 과제에서 측정한 Jitt, Shim, NHR 간에 피어슨 상관분석 (Pearson correlation analysis)을 실시하였다. 통계 프로그램으로는
SPSS 23.0 프로그램(IBM-SPSS Inc.)을 활용하였고, 유의수준은 .05 로 하였다.

\section{연구결과}

\section{성별 및 과제에 따른 켑스트럼 및 스펙트럼 측정치}

$\mathrm{ADSV}$ 를 활용한 켑스트럼 및 스펙트럼 측정치의 기술 통계치와 성별 간 비교 결과는 모음 발성 과제(Table 2)와 문단 읽기 과제(Table 3)에 따라 각각 제시되어 있다. 모음 발성 과제에서 성별 간 비교 를 수행한 결과, 남성의 $\mathrm{CPP}, \sigma \mathrm{CPP}, \mathrm{CPP}_{\max }, \mathrm{CPP}_{\min }, \mathrm{SR}, \mathrm{SR}_{\max }, \mathrm{SR}_{\min }$, $\sigma \mathrm{CPP} / \mathrm{Avg}$, Slope, $\sigma$ Slope, $\sigma \mathrm{CI}, \mathrm{NHR}$ 측정치가 더 높았던 반면, 여 성의 $\mathrm{CPP} \mathrm{F} 0, \mathrm{CPP} / \mathrm{Avg}, \mathrm{CI}$ 측정치가 더 높았다. 한편 $\sigma \mathrm{SR}, \sigma \mathrm{CPP}$ $\mathrm{F} 0$, Jitt, Shim의 경우 성별 간 차이가 없었다.

\section{성별 및 문단 내 위치에 따른 비교}

성별과 문단 내 위치에 따른 음향학적 측정치의 차이가 있는지 알아보기 위해 이원 다변량분석을 수행한 결과, 성별(Wilk's $\lambda=.088$,

Table 2. Descriptive data and group comparison of cepstral and spectral measures according to gender in vowel production task

\begin{tabular}{|c|c|c|c|c|}
\hline & Male & Female & $t$ & $p$-value \\
\hline $\mathrm{CPP}(\mathrm{dB})$ & $14.614 \pm 1.557$ & $12.210 \pm 1.438$ & 9.622 & $<.001^{* * *}$ \\
\hline$\sigma \mathrm{CPP}(\mathrm{dB})$ & $.750 \pm .265$ & $.524 \pm .277$ & 4.986 & $<.001^{* * *}$ \\
\hline $\mathrm{CPP}_{\max }(\mathrm{dB})$ & $16.216 \pm 1.367$ & $13.417 \pm 1.352$ & 12.352 & $<.001^{* * *}$ \\
\hline $\mathrm{CPP}_{\min }(\mathrm{dB})$ & $12.216 \pm 2.281$ & $10.679 \pm 1.847$ & 4.442 & $<.001^{* * *}$ \\
\hline $\mathrm{SR}(\mathrm{dB})$ & $34.757 \pm 4.639$ & $31.549 \pm 4.072$ & 4.409 & $<.001^{* * *}$ \\
\hline$\sigma S R(d B)$ & $1.598 \pm .566$ & $1.505 \pm .538$ & 1.015 & .312 \\
\hline$S R_{\text {max }}(d B)$ & $38.985 \pm 4.869$ & $35.556 \pm 4.215$ & 4.519 & $<.001^{* * *}$ \\
\hline$S R_{\min }(\mathrm{dB})$ & $30.535 \pm 4.028$ & $27.767 \pm 3.701$ & 4.294 & $<.001^{* * *}$ \\
\hline CPP FO (Hz) & $112.585 \pm 13.159$ & $208.566 \pm 16.123$ & -39.133 & $<.001^{* * *}$ \\
\hline бCPP FO (Hz) & $1.232 \pm 3.330$ & $2.334 \pm 4.615$ & -1.642 & .103 \\
\hline CPP/Avg (Hz) & $15.687 \pm 2.049$ & $16.518 \pm 1.447$ & -2.813 & $.006^{* *}$ \\
\hline oCPP/Avg (Hz) & $.758 \pm .243$ & $.544 \pm .276$ & 4.957 & $<.001^{* * *}$ \\
\hline Slope & $-2.069 \pm 0.879$ & $-2.971 \pm .550$ & 7.381 & $<.001^{* * *}$ \\
\hline oSlope & $.347 \pm .316$ & $.209 \pm .163$ & 3.294 & $.001^{* *}$ \\
\hline $\mathrm{Cl}(\mathrm{Hz})$ & $62.653 \pm .571$ & $62.884 \pm .558$ & -2.450 & $.015^{*}$ \\
\hline$\sigma \mathrm{Cl}(\mathrm{Hz})$ & $.231 \pm .058$ & $.203 \pm .047$ & 3.191 & $.002^{* *}$ \\
\hline Jitt (\%) & $.650 \pm .504$ & $.816 \pm .624$ & -1.756 & .081 \\
\hline Shim (\%) & $3.084 \pm 1.190$ & $3.137 \pm 1.055$ & -.281 & .779 \\
\hline NHR & $.132 \pm .019$ & $.123 \pm .021$ & 2.876 & $.005^{* *}$ \\
\hline
\end{tabular}

Values are presented as mean \pm SD.

$\mathrm{CPP}=$ cepstral peak prominence; $\sigma=$ standard deviation; $\mathrm{SR}=$ low/high spectral ratio; CPP F0=mean CPP F0; $\mathrm{CPP} / \mathrm{Avg}=$ average $\mathrm{CPP}$; Slope=regression slope; $\mathrm{Cl}=$ cepstral intensity; Jitt=jitter percent; Shim=shimmer percent; NHR=noise-to-harmonic ratio.

${ }^{*} p<.0 .05,{ }^{* *} p<.01,{ }^{* * *} p<.001$. 
Table 3. Descriptive data of cepstral and spectral measures according to gender and position in passage reading task

\begin{tabular}{|c|c|c|}
\hline & Male & Female \\
\hline \multicolumn{3}{|l|}{ Front } \\
\hline $\mathrm{CPP}(\mathrm{dB})$ & $7.043 \pm 1.172$ & $6.833 \pm .716$ \\
\hline$\sigma \mathrm{CPP}(\mathrm{dB})$ & $4.124 \pm .409$ & $3.529 \pm .284$ \\
\hline $\mathrm{CPP}_{\max }(\mathrm{dB})$ & $14.774 \pm 1.277$ & $13.216 \pm .931$ \\
\hline $\mathrm{CPP}_{\min }(\mathrm{dB})$ & $.019 \pm .020$ & $.045 \pm .045$ \\
\hline $\mathrm{SR}(\mathrm{dB})$ & $33.160 \pm 2.637$ & $30.422 \pm 2.176$ \\
\hline$\sigma S R(d B)$ & $9.657 \pm 1.102$ & $9.769 \pm .954$ \\
\hline$S R_{\max }(d B)$ & $51.587 \pm 3.983$ & $50.459 \pm 3.421$ \\
\hline $\mathrm{SR}_{\min }(\mathrm{dB})$ & $-2.186 \pm 5.523$ & $-10.421 \pm 5.612$ \\
\hline CPP FO (Hz) & $148.768 \pm 17.624$ & $207.699 \pm 13.901$ \\
\hline бCPP FO (Hz) & $64.143 \pm 17.204$ & $31.218 \pm 5.650$ \\
\hline CPP/Avg (Hz) & $9.125 \pm 1.100$ & $11.226 \pm .802$ \\
\hline$\sigma \mathrm{CPP} / \mathrm{Avg}(\mathrm{Hz})$ & $3.367 \pm .576$ & $3.737 \pm .301$ \\
\hline Slope & $-6.882 \pm 1.507$ & $-6.109 \pm .708$ \\
\hline oSlope & $4.656 \pm .613$ & $4.007 \pm .477$ \\
\hline $\mathrm{Cl}(\mathrm{Hz})$ & $61.833 \pm .548$ & $61.709 \pm .445$ \\
\hline$\sigma \mathrm{Cl}(\mathrm{Hz})$ & $1.026 \pm .232$ & $1.111 \pm .181$ \\
\hline \multicolumn{3}{|l|}{ Rear } \\
\hline $\mathrm{CPP}(\mathrm{dB})$ & $7.341 \pm 1.070$ & $6.571 \pm .772$ \\
\hline$\sigma \mathrm{CPP}(\mathrm{dB})$ & $3.867 \pm .359$ & $3.496 \pm .295$ \\
\hline $\mathrm{CPP}_{\max }(\mathrm{dB})$ & $14.624 \pm 1.243$ & $13.360 \pm 1.200$ \\
\hline $\mathrm{CPP}_{\min }(\mathrm{dB})$ & $.026 \pm .031$ & $.038 \pm .038$ \\
\hline $\mathrm{SR}(\mathrm{dB})$ & $33.066 \pm 2.789$ & $30.847 \pm 2.651$ \\
\hline$\sigma \mathrm{SR}(\mathrm{dB})$ & $11.720 \pm 1.348$ & $12.090 \pm 1.268$ \\
\hline $\mathrm{SR}_{\max }(\mathrm{dB})$ & $52.056 \pm 3.360$ & $52.749 \pm 4.104$ \\
\hline$S R_{\min }(d B)$ & $-6.668 \pm 4.970$ & $-14.167 \pm 5.015$ \\
\hline CPP FO (Hz) & $138.052 \pm 13.529$ & $206.639 \pm 15.863$ \\
\hline$\sigma \mathrm{CPP} F 0(\mathrm{~Hz})$ & $52.530 \pm 16.820$ & $29.319 \pm 5.977$ \\
\hline CPP/Avg (Hz) & $9.172 \pm 1.123$ & $10.933 \pm .901$ \\
\hline$\sigma C P P / A v g(H z)$ & $3.275 \pm .520$ & $3.694 \pm .319$ \\
\hline Slope & $-6.336 \pm 1.434$ & $-6.026 \pm .809$ \\
\hline бSlope & $4.382 \pm .660$ & $3.826 \pm .527$ \\
\hline $\mathrm{Cl}(\mathrm{Hz})$ & $61.957 \pm .566$ & $61.807 \pm .517$ \\
\hline$\sigma \mathrm{Cl}(\mathrm{Hz})$ & $.914 \pm .271$ & $1.000 \pm .172$ \\
\hline
\end{tabular}

Values are presented as mean $\pm \mathrm{SD}$.

$\mathrm{CPP}=$ cepstral peak prominence; $\sigma=$ standard deviation; $\mathrm{SR}=$ low/high spectral ratio; CPP F0=mean CPP F0; CPP/Avg=average CPP; Slope=regression slope; $\mathrm{Cl}=$ cepstral intensity.

$p<.001)$, 문단 내 위치(Wilk's $\lambda=.384, p<.001$ )에 따른 유의한 주 효과가 있었으며, 유의한 상호작용효과(Wilk's $\lambda=.829, p<.001)$ 또 한 나타났다. 상호작용효과는 $\mathrm{CPP}(p=.013), \sigma \mathrm{CPP}(p=.006), \mathrm{SR}_{\max }$ ( $p=.039)$, CPP F0 ( $p=.008), \sigma \mathrm{CPP} \mathrm{F0}(p=.001)$ 에서 나타났다(Figure 1). 상호작용효과가 없었던 변수들의 주효과를 살펴보면, 남성 의 $\mathrm{CPP}_{\max }(p<.001), \mathrm{SR}(p<.001), \mathrm{SR}_{\min }(p<.001)$, $\sigma$ Slope $(p<.001)$, $\mathrm{CI}(p=.027)$ 가 더 높았던 반면, 여성의 $\mathrm{CPP}_{\min }(p<.001), \mathrm{CPP} / \mathrm{Avg}$
Table 4. Pearson correlation coefficient between acoustic measures derived from vowel phonation and passage reading tasks

\begin{tabular}{lllll}
\hline & $\mathrm{CPP}_{\mathrm{F}}(\mathrm{dB})$ & $\mathrm{SR}_{\mathrm{F}}(\mathrm{dB})$ & $\mathrm{CPP}_{\mathrm{R}}(\mathrm{dB})$ & $\mathrm{SR}_{\mathrm{R}}(\mathrm{dB})$ \\
\hline Jitt $(\%)$ & $-.306^{* * *}$ & -.016 & $-.326^{* * *}$ & .025 \\
Shim $(\%)$ & $-.241^{* *}$ & -.125 & $-.268^{* *}$ & -.156 \\
NHR & .004 & .140 & .013 & .043 \\
CPPv $(\mathrm{dB})$ & $.393^{* * *}$ & $.218^{* *}$ & $.537^{* * *}$ & .128 \\
SRv $(\mathrm{dB})$ & -.009 & $.586^{* * *}$ & .048 & $.580^{* * *}$ \\
\hline
\end{tabular}

$\mathrm{CPP}=$ cepstral peak prominence; $\mathrm{SR}=$ low/high spectral ratio; $\mathrm{F}=$ front; $\mathrm{R}=$ rear; $V=$ vowel; Jitt=jitter percent; Shim=shimmer percent; NHR=noise-to-harmonic ratio.

${ }^{* *} p<.01,{ }^{* * *} p<.001$.

$(p<.001), \sigma \mathrm{CPP} / \mathrm{Avg}(p<.001), \sigma \mathrm{CI}(p=.001)$ 가 더 높았다. 또한 앞 문장의 $\mathrm{SR}_{\min }(p<.001), \sigma \mathrm{Slope}(p=.006), \sigma \mathrm{CI}(p=.001)$ 가 더 높았 던 반면, 뒷 문장의 $\sigma \mathrm{SR}(p<.001)$, Slope $(p=.024)$ 가 더 높았다.

\section{과제에 따른 켑스트럼 및 스펙트럼 측정치 간 상관관계}

모음 발성과 문단 읽기 과제를 이용하여 측정한 대표적인 켑스트 럼 및 스펙트럼 측정치 간의 상관관계를 피어슨 상관계수를 통해 살펴본 결과(Table 4), 문단 읽기 시 CPP와 모음 발성 시 Jitt (앞 문 장 $=-.306$, 뒷 문장 $=-.326$ ), Shim (앞 문장 $=-.241$, 뒷 문장 $=-.268$ ) 사이에 '약함' 수준의 음의 상관관계가 있었다. 한편 모음 발성의 $\mathrm{CPP}$ 와 문단 읽기의 $\mathrm{CPP}$ 간에는 '약함-중간' 수준의 양의 상관관 계가(앞 문장 $=.393$, 뒷 문장 $=.537$ ), 모음 발성의 SR과 문단 읽기의 SR 간에는 '중간' 수준의 양의 상관관계가 있었다(앞 문장 $=.586$, 뒷 문장 $=.580)$.

\section{논의 및 결론}

본 연구에서는 한국 정상 성인에서 한국어 모음/// 연장 발성과 표준문단 읽기 과제를 시행하여 $\mathrm{ADSV}$ 를 통해 측정한 켑스트럼 및 스펙트럼 측정치의 정상 규준 자료를 제시하고자 하였다. 아울 러 문단 읽기 과제의 경우 문단 내 위치와 성별에 따른 측정치를 비 교하여 차이를 확인하고자 하였다. 마지막으로, 상이한 두 과제를 이용한 선별된 측정치들 간에 상관관계가 있는지의 여부를 확인하 고자하였다.

먼저 주요 측정치라 할 수 있는 $\mathrm{CPP}$ 의 평균 측정치는 남성의 경 우 모음, 앞 문장, 뒷 문장에서 각각 $14.614 \mathrm{~dB}, 7.043 \mathrm{~dB}, 7.341 \mathrm{~dB}$ 이 었으며, $\mathrm{SR}$ 의 평균 측정치는 각각 $34.757 \mathrm{~dB}, 33.160 \mathrm{~dB}, 33.066 \mathrm{~dB}$ 이었다. 한편 여성의 $\mathrm{CPP}$ 는 각각 $12.210 \mathrm{~dB}, 6.833 \mathrm{~dB}, 6.571 \mathrm{~dB}, \mathrm{SR}$ 은 각각 $31.549 \mathrm{~dB}, 30.422 \mathrm{~dB}, 30.847 \mathrm{~dB}$ 이었다. 이렇듯 성별과 무 관하게 모음의 $\mathrm{CPP}$ 와 $\mathrm{SR}$ 측정치가 연결발화에 비해 높은 것은 모 

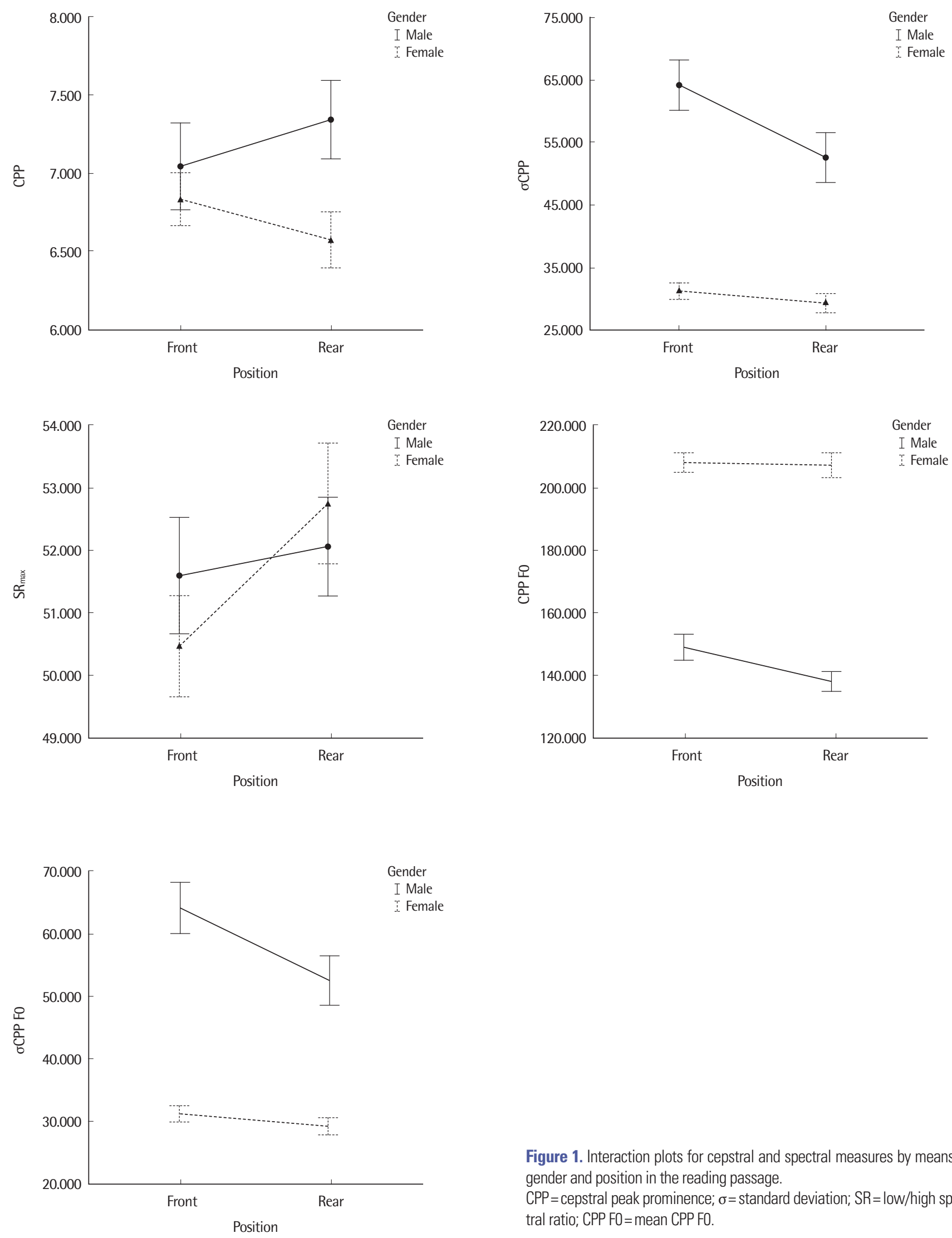

Figure 1. Interaction plots for cepstral and spectral measures by means of gender and position in the reading passage.

$\mathrm{CPP}=$ cepstral peak prominence; $\sigma=$ standard deviation; $\mathrm{SR}=$ low/high spectral ratio; CPP FO= mean CPP FO. 
음샘플에서 더욱 많은 유성 구간(voice period)이 포함되어 자연스 러운 현상으로 보이며, 이러한 경향은 다양한 중증도를 가진 음성 장애군이나 정상 대조군을 막론하고 모음과 연결발화 샘플을 모 두 포함한 국내 선행연구들에서 공히 보고된다(Choi \& Choi, 2016;

Kim et al., 2015, 2016, 2017; Lee et al., 2017b; Shim et al., 2016; Yu et al., 2017). 특히 정상 화자에 대해 Choi와 Choi (2016)에서 제시된 측정치와 성별 간 비교 결과를 고려하였을 때, 본 연구의 결과에서 도 남성과 여성 모두에서 이와 매우 유사한 측정치와 경향이 관찰 된 것으로 보인다.

모음 발성 과제에서의 성별에 따른 비교를 살펴보면, 대부분의 $\mathrm{CPP}$ 와 SR 측정치, 그리고 $\mathrm{NHR}$ 에서 남성의 측정치가 여성에 비해 높았던 반면, $\mathrm{CPP}_{\min }$ 의 경우 여성의 측정치가 높았는데, 이는 부분 적으로는 남성에서 더욱 큰 $\mathrm{CPP}, \sigma \mathrm{SR}, \mathrm{NHR}$ 을 보고한 국내의 선행 연구들과 일치하는 결과이다(Choi \& Choi, 2016; Kim, 2009). 여기 서 주목할 만한 것은 같은 모음샘플에 대한 분석이라 할지라도 분 석 방법에 따른 차이가 있었다는 점이다. 구체적으로는 남성 집단 에서 켑스트럼 기반의 CPP 측정치가 더욱 높음에도 불구하고 전 통적인 시간기반 분석을 이용한 측정치인 NHR이 더욱 높았는데, 분석방법에 따른 이러한 간극은 선행연구에서도 보고되어 왔다 (Jannetts \& Lowit, 2014; Shim, Jang, Shin, \& Ko, 2015). 남성의 CPP 가 더욱 높은 점은 정상 여성, 특히 연령대를 막론하고 성문 틈(glottal chink)에 기인한 다소간의 기식성(breathiness)이 흔히 보고된 다는 점을 감안할 때 납득할만하다(Biever \& Bless, 1989; Lee et al., 2015). 다만 이 같은 결과는 몇 가지의 음향학적 측정치를 기반으로 어느 성별의 음성의 질이 더욱 좋다 혹은 나쁘다고 단정하는 것이 성급한 결론일 수 있다는 견해를 지지하는 것이며, 숙련된 전문가 의 청지각적 평정을 포함한 다면적 평가의 필요성을 뒷받침하는 것 으로 보인다. 추후 기식성에 대한 청지각적 평정 결과를 고려하여 음향학적 분석방법에 따른 성별 차에 대한 보다 정밀한 후속연구 를 진행해볼수 있을 것으로 보인다.

성별 및 문단 내 위치에 따른 유의한 상호작용 효과를 보인 변수 들 중 주목할 만 한 변수로 $\mathrm{CPP} \mathrm{F0와} \sigma \mathrm{CPP}$ F0가 있다. 특히 남성의 경우 모음에서는 CPP F0가 평균 $112.585 \mathrm{~Hz}$ 로 문헌에서 알려진 바 와 큰 차이가 없었지만, 문단 읽기 과제에서는 앞 문장의 경우 평균 $148.768 \mathrm{~Hz}$, 뒷 문장의 경우 $138.052 \mathrm{~Hz}$ 로 이보다 다소 높은 경향 을 보였다. 반면, 여성의 경우 모음에서는 평균 $208.566 \mathrm{~Hz}$ 로 역시 알려진 바와 크게 다르지 않고, 앞 문장에서 평균 $207.699 \mathrm{~Hz}$, 뒷 문장에서 평균 $206.639 \mathrm{~Hz}$ 로 이와 유사하였다. 이러한 차이는 CPP F0 분석이 적용되는 주파수의 범위가 $60-300 \mathrm{~Hz}$ 로서, 흔히 알려진 남성의 평균 기본 주파수, 그리고 전후의 동적 범위(dynamic range)
를 고려할 때 지나치게 넓은 범위의 음향학적 정보를 분석에 포함 하기 때문인 것으로 풀이된다. 이와 같은 맥락에서 문단 읽기에서 $\mathrm{CPP} / \mathrm{Avg}$ 와 그 표준편차 또한 $60-300 \mathrm{~Hz}$ 의 분석 범위가 적용되므 로 $\mathrm{CPP}$ 의 경우와는 상이한 성별 차이의 경향을 나타낸 것으로 보 인다. 선행연구들에서도 이와 같은 점을 지적하면서 남성의 경우 동적 범위의 상한을 $200 \mathrm{~Hz}$ 로 낮추어 설정할 것을 제안하고 있다 (Awan, 2011; Garrett, 2013). 이 상한은 ADSV 프로그램 메뉴 중 옵 션의 고급 설정(advanced option)에서 킵스트럼 피크 추출의 최대 값(cepstral peak extraction range maximum) 수치를 바꾸어 조정 이 가능하다. 다만 이는 정상 화자에 국한하였을 경우에만 타당성 을 가진 주장으로 보이며, 음성장애 환자에서 병리적 증상으로서 통상적인 범위에 비해 더욱 높은 주파수 대역의 기본주파수를 산 출하는 경우, 예컨대 변성발성장애(mutational falsetto)나 성대구 증(sulcus vocalis)에서 다소 고음역대의 발화 기본주파수를 보이 는 경우에는 이러한 성별 차를 고려하더라도 본래의 설정 $(300 \mathrm{~Hz}$ 의 상한)을 유지하는 것이 보다 바람직할 것으로 보인다.

문단 읽기 과제에서 위치에 따른 차이를 살펴 본 결과, 앞 문장의 $\mathrm{SR}_{\min }, \sigma$ Slope, $\sigma \mathrm{CI}$ 가 더 높았던 반면, 뒷 문장의 $\sigma \mathrm{SR}$, Slope가 더 높 았다. 이러한 결과는 두 위치의 문장의 길이나 장애음의 비율 측면 에서 매우 유사함(Lee et al., 2017a)에도 불구하고 도출된 결과라는 점에서 더욱 흥미롭다. 또한 $\mathrm{CPP}, \sigma \mathrm{CPP}, \mathrm{SR}_{\max }, \mathrm{CPP} F 0, \sigma \mathrm{CPP} F$ 의 경우 성별과 위치 간 유의한 상호작용 효과가 존재하였다. 특히 남 성의 $\mathrm{CPP}$ 가 뒷 문장에서 증가한 반면 여성은 감소하였고, $\sigma \mathrm{CPP}$ 의 감소 폭은 여성에 비해 남성이 더욱 컸으며, $\mathrm{SR}_{\max }$ 의 증가 폭은 여성 이 남성에 비해 더욱 컸다는 점이 주목할 만하다. 이러한 결과는 한 편으로는 앞 문장부터 뒷 문장까지 연결 발화를 산출하는 동안 음 성 피로의 효과로 인한 기식성 증가를 반영하는 것일 수 있으며, 다 른 한편으로는 이러한 음성 피로 효과가 여성에서 더욱 두드러질 수 있음을 시사한다. 또한 음성 피로 효과로 인해 문단 내에서 뒤로 갈수록 음성의 질 저하가 야기된다고 가정할 때, 이에 대처하여 음 성의 질을 보정하고자 하는 보상적 전략(compensatory strategies) 이 성별 또는 개인에 따라 다소 차이가 있을 수 있다는 점을 일부 뒷 받침하는 결과라고 본다. 아울러 본 연구에서는 정상 음성에 대한 측정치를 비교하였다는 점을 고려하면, 앞 부분의 문장 산출 시 $\mathrm{CPP}$ 측정치가 상대적으로 더욱 높은 대상자가 뒷 부분에서 감소 폭이 더욱 두드러지게 보일 가능성 또한 존재한다. 다만 한 선행연 구에서는 중증도를 통제한 상태에서는 음성장애 환자군과 정상 대 조군 간 켑스트럼 측정치의 유의한 차이는 없고, 문단 내 위치에 따 른 차이만 존재하는 것으로 보고하였다(Lee et al., 2017a). 따라서, 이외에도 이러한 위치에 따른 음향학적 측정치 차이에 영향을 줄 
수 있는 다른 요인들을 탐색할 필요가 있다고 본다.

마지막으로 다양한 측정치 간의 상관관계를 살펴본 결과, 상이 한 과제를 통해 측정한 음향학적 측정치들 간에 '약함-중간' 수준 의 양 혹은 음의 유의한 상관관계가 관찰되었다. 물론, 상관관계의 강도가 크지 않다는 점은 다양한 과제를 이용한 음향학적 평가의 필요성을 시사하는 것으로 보는 것이 일면 타당하다(Choi \& Choi, 2016). 그러나 다른 한편으로 특히 $\mathrm{CPP}$ 의 경우, 앞 문장과 뒷 문장 모두에서 강하지는 않으나 유의한 상관관계가 나타난 것은 과제 간 상관관계가 없음을 보고한 한 국내 선행연구와는 상반된 결과 이다(Choi \& Choi, 2016). 이는 해당 선행연구에서 같은 '가을' 문 단을 과제로 사용하였으나, 문단 전체를 켑스트럼 분석의 대상으로 삼은 데 따른 것으로 풀이된다. 음소 구성 측면에서 보다 구체적으로 장애음의 비율을 살펴보면, 앞 문장은 $53.85 \%$, 뒷 문장은 $51.61 \%$ 로 비교적 서로 유사하다(Lee et al., 2017a). 즉, 본 연구에서와 같이 문 장 수준에서 관찰된 모음 측정치와의 상관관계가, 해당 연구에서 는 전체 문단 수준으로 분석의 샘플이 커지면서 장애음의 비율이 달라지고, 이에 따라 과제별 측정치 간의 상관관계가 희석되었을 가능성을 배제할 수 없다고 여겨진다.

이는 나아가 전체 문단 수준의 긴 연결발화보다는 비교적 짧은 문장 샘플을 켑스트럼 분석에 이용하는 것이 더욱 적절할 가능성 을 시사하는 것으로 보인다. 한 문단 내의 앞과 뒤의 문장 모두에서 공히 켑스트럼 및 스펙트럼 측정치가 전문가의 청지각적 평정치를 유의하게 예측한다는 선행연구 또한 이를 뒷받침하며(Lee et al., 2017a), 다른 여러 국외연구들에서도 표준 문단의 앞부분 문장을 활 용하고 있다는 점 또한 이러한 가설을 지지한다(Heman-Ackah et al., 2014). 다만 본 연구에서 일부 확인된 것처럼, 전체 문단을 녹음 하되 각각 다른 위치에서 문장 수준의 샘플을 따로이 추출하여 분 석한다면, 위치에 따른 대상자의 음성의 질 변화를 더욱 상세히 살 펴볼 수 있을 것이며, 이러한 차이에 대한 정보는 결국 대상자에게 맞는 개별화된 중재 서비스를 제공하는 데 일조할 것으로 여겨진다.

종합해보면 본 연구는 켑스트럼 및 스펙트럼 측정치의 정상 규 준 자료를 마련하였다는 점에서 임상에서 이러한 측정치를 더욱 활 발하게 활용할 수 있는 토대를 마련하였다는 데에 의의가 있다고 여겨진다. 남성은 모음 발성 과제에서 여성에 비해 높은 $\mathrm{CPP}$ 와 SR 관련 측정치를 보였으며, 과제에 따른 차이, 그리고 성별과 문단 내 위치에 따른 상호작용 효과가 있었으므로, 켑스트럼 및 스펙트럼 측정치를 활용한 연구 및 임상에서 특정 중재의 효과를 살펴볼 때 본 연구에서 제시된 전반적인 수치뿐만 아니라 이러한 상호작용을 고려하여야 할 것으로 보인다. 다만 본 연구에서는 녹음 기자재나 환경에 따른 차이, 여성에서 중요한 월경 주기나 폐경 여부에 따른
차이, 장애음이나 공명음의 포함 비율이 다른 말 자료에 따른 차이, 노화에 따른 차이 등을 고려하지 못한 한계가 명확하므로, 이를 고 려한 켑스트럼 및 스펙트럼 측정치의 후속 연구가 필요할 것으로 판단된다. 또한 $\mathrm{CPP}$ 와 SR 이외의 변수들의 경우 정상 성인의 측정 치를 제시하는 데 주안점을 두었으므로, 이들이 갖는 임상적 가치 에 대한 연구가 추가적으로 필요할 것으로 보인다.

\section{REFERENCES}

Awan, S. N. (2011). Analysis of dysphonia in speech and voice: an application guide. Montvale, NJ: KayPENTAX.

Awan, S. N., Roy, N., Zhang, D., \& Cohen, S. M. (2016). Validation of the cepstral spectral index of dysphonia (CSID) as a screening tool for voice disorders: development of clinical cutoff scores. Journal of Voice, 30, 130144 .

Biever, D. M., \& Bless, D. M. (1989). Vibratory characteristics of the vocal folds in young adult and geriatric women. Journal of Voice, 3, 120-131.

Brinca, L. F., Batista, A. P. F., Tavares, A. I., Gonçalves, I. C., \& Moreno, M. L. (2014). Use of cepstral analyses for differentiating normal from dysphonic voices: a comparative study of connected speech versus sustained vowel in European Portuguese female speakers. Journal of Voice, 28, 282-286.

Choi, S. H., \& Choi, C. H. (2016). The effect of gender and speech task on cepstral-and spectral-measures of Korean normal speakers. Audiology \& Speech, 12, 157-163.

Faul, F., Erdfelder, E., Buchner, A., \& Lang, A. G. (2009). Statistical power analyses using $\mathrm{G}^{\star}$ Power 3.1: tests for correlation and regression analyses. Behavior Research Methods, 41, 1149-1160.

Fraile, R., \& Godino-Llorente, J. I. (2014). Cepstral peak prominence: a comprehensive analysis. Biomedical Signal Processing and Control, 14, 42-54.

Garrett, R. K. (2013). Cepstral-and spectral-based acoustic measures of normal voices (Doctoral dissertation). The University of Wisconsin-Milwaukee, Milwaukee, WI.

Heman-Ackah, Y. D., Michael, D. D., \& Goding, G. S. (2002). The relationship between cepstral peak prominence and selected parameters of dysphonia. Journal of Voice, 16, 20-27.

Heman-Ackah, Y. D., Sataloff, R. T., Laureyns, G., Lurie, D., Michael, D. D., Heuer, R., ... \& Lyons, K. (2014). Quantifying the cepstral peak prominence, a measure of dysphonia. Journal of Voice, 28, 783-788.

Hillenbrand, J., Cleveland, R. A., \& Erickson, R. L. (1994). Acoustic correlates of breathy vocal quality. Journal of Speech, Language, and Hearing Research, 
37, 769-778.

Hirano, M. (1981). Clinical examination of voice. New York, NY: Springer.

Jannetts, S., \& Lowit, A. (2014). Cepstral analysis of hypokinetic and ataxic voices: correlations with perceptual and other acoustic measures. Journal of Voice, 28, 673-680.

Kang, Y., \& Koo, B. S. (2015). Acoustic analysis of voice change according to extent of thyroidectomy. Phonetics and Speech Sciences, 7, 77-83.

KayPENTAX. (2011). Analysis of dysphonia in speech and voice Model 5109: software instruction manual. Montvale, NJ: KayPENTAX.

Kim, G. H., Lee, Y. W., Bae, I. H., Park, H. J., Lee, J. S., Wang, S. G., \& Kwon, S. B. (2017). A study of cepstral peak prominence characteristics in ADSV, SpeechTool and Praat. Journal of Speech-Language \& Hearing Disorders, 26, 99-111.

Kim, G. H., Lee, Y. W., Bae, I. H., Park, H. J., Lee, J. S., Wang, S. G., \& Kwon, S. B. (2016). A cepstral analysis of voices with glottic cancer and laryngeal leukoplakia: sustained vowels and continuous speech. Journal of SpeechLanguage \& Hearing Disorders, 25, 135-145.

Kim, H. (2012). Neurologic speech-language disorders. Seoul: Sigmapress.

Kim, J. (2009). Acoustic characteristics of the voices of Korean normal adults by gender on MDVP. Phonetics and Speech Sciences, 1, 147-157.

Kim, T. H., Choi, J. I., Lee, S. H., \& Jin, S. M. (2015). Comparison of vowel and text-based cepstral analysis in dysphonia evaluation. The Journal of the Korean Society of Logopedics and Phoniatrics, 26, 117-121.

Lee, S. J., Cho, Y., Song, J. Y., Lee, D., Kim, Y., \& Kim, H. (2015). Aging effect on korean female voice: acoustic and perceptual examinations of breathiness. Folia Phoniatrica et Logopaedica, 67, 300-307.

Lee, S. J., Choi, H. S., Kim, H., Byeon, H. K., Lim, S. E., \& Yang, M. K. (2016). Korean version of the Voice Activity and Participation Profile (K-VAPP): a validation study. Communication Sciences \& Disorders, 21, 695-708.

Lee, S. J., Lim, S. E., \& Choi, H. S. (2017a). A comparison of cepstral and spectral measures according to measurement position in a reading passage. Communication Sciences \& Disorders, 22, 818-826.

Lee, S. J., Lim, S. E., \& Choi, H. S. (2017b). Responsiveness of the Korean version of the Voice Activity and Participation Profile (K-VAPP) after surgical intervention. Communication Sciences \& Disorders, 22, 379-390.
Lowell, S. Y., Colton, R. H., Kelley, R. T., \& Mizia, S. A. (2013). Predictive value and discriminant capacity of cepstral-and spectral-based measures during continuous speech. Journal of Voice, 27, 393-400.

Moers, C., Möbius, B., Rosanowski, F., Nöth, E., Eysholdt, U., \& Haderlein, T. (2012). Vowel-and text-based cepstral analysis of chronic hoarseness. Journal of Voice, 26, 416-424.

Oppenheim, A. V., \& Schafer, R. W. (2004). From frequency to quefrency: a history of the cepstrum. IEEE Signal Processing Magazine, 21, 95-106.

Park, M. C., Mun, M. K., Lee, S. H., \& Jin, S. M. (2013). Clinical usefulness of cepstral analysis in dysphonia evaluation. Korean Journal of Otorhinolaryngology-Head and Neck Surgery, 56, 574-578.

Pyo, H. Y., Sim, H. S., Song, Y. K., Yoon, Y. S., Lee, E. K., Lim S. E., ... \& Choi, H. S. (2002). The acoustic study on the voices of Korean normal adults. Speech Sciences, 9, 179-192.

Sauder, C., Bretl, M., \& Eadie, T. (2017). Predicting voice disorder status from smoothed measures of cepstral peak prominence using Praat and analysis of dysphonia in speech and voice (ADSV). Journal of Voice, 31, 557-566.

Seo, I. H, Jung, D., Han, H. J., Moon, J. H., Chung, P. S., \& Lee, S. J. (2016). Analysis of acoustic parameters to objectively reflect the change of voice quality before and after surgery in benign vocal fold mucosal disorders. Korean Journal of Otorhinolaryngology-Head and Neck Surgery, 59, 775779.

Shim, H. J., Jang, H. R., Shin, H. B., \& Ko, D. H. (2015). Cepstral, spectral and time-based analysis of voices of esophageal speakers. Folia Phoniatrica et Logopaedica, 67, 90-96.

Shim, H. J., Jung, H., Lee, S. A., Choi, B. H., Heo, J. H., \& Ko, D. H. (2016). Cepstral and spectral analysis of voices with adductor spasmodic dysphonia. Phonetics and Speech Sciences, 8, 73-80.

Watts, C. R., \& Awan, S. N. (2011). Use of spectral/cepstral analyses for differentiating normal from hypofunctional voices in sustained vowel and continuous speech contexts. Journal of Speech, Language, and Hearing Research, 54, 1525-1537.

Yu, M., Choi, S. H., Choi, C. H., \& Lee, K. (2017). Usefulness of cepstral acoustic index for estimating objective dysphonia severity. Communication Sciences \& Disorders, 22, 587-596. 


\section{국문초록}

\section{모음 발성 및 문단 읽기 과제 시 한국 성인의 켑스트럼 및 스펙트럼 측정치 정상 규준 연구}

이승진 ${ }^{\prime}$ 표화영'

'연세대학교 의과대학 이비인후과학교실 및 후두음성언어의학연구소, ${ }^{2}$ 조선대학교 언어치료학과

배경 및 목적: 본 연구에서는 한국 정상 성인에서 모음 발성 및 문단 읽기 과제 시 켑스트럼 및 스펙트럼 측정치의 정상 규준 자료를 마 련하고자 하였다. 또한 표준문단 내 측정위치와 성별에 따른 측정치를 비교하고, 각 과제별 측정치 간의 상관관계를 알아보았다. 방법: 서울 지역 거주 중인 정상 한국 성인 남녀 각 72 명에게 모음/가를 5 초간 발성하고 표준문단 '가을'을 읽게 하였다. 문단 내 앞과 뒤 문장 과 모음 샘플에서 $\mathrm{ADSV}$ 를 이용하여 켑스트럼 및 스펙트럼 변수를 측정하였다. 성별과 문단 내 위치에 따라 각 측정치를 비교하고, 각 과제에 따른 측정치 간의 상관관계를 살펴보았다. 결과: 모음에서는 남성의 $\mathrm{CPP}$ 와 $\mathrm{L} / \mathrm{H}$ 비율 관련 측정치가 더 높았던 반면, 여성의 $\mathrm{CPP} \mathrm{F} 0, \mathrm{CPP} / \mathrm{Avg}$ 가 더 높았다. CPP와 표준편차, $\mathrm{L} / \mathrm{H}$ 비율 최댓값에서는 유의한 상호작용 효과가 있었다. 남성의 $\mathrm{CPP}$ 최댓값이 높았던 반면, 여성의 CPP 최솟값이 높았다. 앞 문장의 $\mathrm{L} / \mathrm{H}$ 비율 최솟값이 높았던 반면, 뒷 문장의 $\mathrm{L} / \mathrm{H}$ 비율 표준편차가 높았다. 과제별 측정치 간에는 약함-중간 수준의 상관관계가 나타났다. 논의 및 결론: 본 연구의 켑스트럼 및 스펙트럼 정상 측정치는 한국인의 음성장애 진 단 및 연구에 기여할 수 있을 것으로 보이며, 과제 및 성별에 따른 차이가 고려되어야 할 것으로 여겨진다.

핵심어: 켑스트럼 분석, 켑스트럼 피크 현저성(CPP), L/H 비율, 정상 규준 자료, 모음 발성, 문단 읽기

\section{참고문헌}

강영애, 구본석(2015). 갑상선 수술범위에 따른 음성의 음향적 분석. 말소리와음성과학, 7,77-83.

김근효, 이연우, 박희준, 배인호, 권순복(2017). ADSV, SpeechTool, Praat 간의 CPP 특성 연구. 언어치료연구, 26, 99-111.

김근효, 이연우, 배인호, 박희준, 이재석, 왕수건, 권순복(2016). 성문암과 후두백반증 음성의 켑스트럼 분석 및 청지각적 평가: 연장모음과 연속발화. 언어치료연구, 25, 135-145.

김재옥(2009). 성별에 따른 한국 정상 성인 음성의 음향학적 평가 기준치. 말소리와음성과학, 1, 147-157.

김태환, 최정임, 이상혁, 진성민(2015). 발성장애 평가 시 /a/ 모음연장발성 및 문장검사의 켑스트럼 분석 비교. 대한후두음성언어의학회지, 26, 117-121. 김향희(2012). 신경언어장애. 서울: 시그마프레스.

박민철, 문명기, 이상혁, 진성민(2013). 음성장애 평가에서 켑스트럼 분석의 임상적 유용성. 대한이비인후과학회지-두경부외과학, 56, 574-578.

서인효, 정동식, 한현주, 문정환, 정필상, 이상준(2016). 성대 양성점막 질환에서 수술 전후음질변화를 객관적으로 반영하는 음향지표 분석. 대한이비

인후과학회지-두경부외과학, 59, 775-779.

심희정, 정훈, S. A. Lee, 최병흔, 허정화, 고도흥(2016). 내전형연축성 발성장애 음성에 대한 켑스트럼과 스펙트럼 분석. 말소리와음성과학, 8, 73-80. 유미옥, 최성희, 최철희, 이경재(2017). 객관적인 음성장애 중증도 측정을 위한 캡스트럼 음향 지표의 유용성. 언어청각장애연구, 22, 587-596.

이승진, 임성은, 최홍식(2017a). 문단 내 위치에 따른 켑스트럼 및 스펙트럼 측정치 비교. 언어청각장애연구, 22, 818-826.

이승진, 임성은, 최홍식(2017b). 수술적 중재 후 음성 활동 및 참여 프로파일-한국판(K-VAPP)의 반응도 연구. 언어청각장애연구, 22, 379-390. 이승진, 최홍식, 김향희, 변형권, 임성은, 양민교(2016). 음성 활동 및 참여 프로파일-한국판(K-VAPP): 타당성 검증 연구. 언어청각장애연구, 21, 695-708. 최성희, 최철희(2016). 한국 정상 화자의 캡스트럼과 스펙트럼 측정치의 성별과 발화 과제 효과. 청능재활, 12, 157-163.

표화영, 심현섭, 송윤경, 윤영선, 이은경, 임성은, 하현령, 최홍식(2002). 한국 성인의 정상 음성에 관한 기본음성 측정치 연구. 음성과학, 9, 179-192. 